\title{
O tratamento que a inclusão educacional do público da educação especial recebe nos Planos Institucionais de Desenvolvimento e Expansão (PIDEs) da Universidade Federal de Uberlândia (UFU)
}

\author{
Márcia Guimarães de Freitas* \\ Lázara Cristina da Silva**
}

\section{Resumo}

Este trabalho apresenta parte dos resultados obtidos em pesquisa desenvolvida no curso de mestrado em educação. Tivemos como objetivo analisar de que forma a inclusão é proposta e implementada pela Universidade Federal de Uberlândia (UFU). Buscamos identificar qual o conceito de inclusão fomentado nos Planos Institucionais de Desenvolvimento e Expansão (PIDEs) e se as metas e açóes previstas nesses documentos contribuem para minimizar as barreiras físicas e atitudinais enfrentadas pelos estudantes com deficiência nesse espaço institucional. Para realização deste trabalho, optou-se pela pesquisa documental utilizando como fonte de dados, os documentos oficiais nacionais e da instituição. Os nacionais foram as legislaçóes reguladoras e orientadoras para a educação em geral e para a superior, portanto foram tomados as leis, decretos, pareceres, instruçóes normativas, notas técnicas, etc. produzidas de 1996 a 2015; e como documentos institucionais, foram utilizadas as duas versóes do PIDE, no período de 2008-2012 e no período de 2010-2015, atas do Conselho Universitário (CONSUN), Estatuto UFU, Regimento Interno e outros documentos. Constatamos que a inclusão, sob os efeitos do processo histórico, torna-se, na atualidade, um imperativo do Estado e chega às universidades, dado que, segundo a visão neoliberal, a educação passa a ser condição para que as pessoas possam operar com a lógica da inclusão em todas as suas ações. Constatamos também que, na UFU, esse imperativo inclusivo se verifica nos documentos (PIDEs) de duas maneiras: através da inclusão social e da acessibilidade como política de inserção e permanência dos estudantes.

Palavras-chave: Universidade Federal de Uberlândia (UFU); Inclusão; Plano Institucional de Desenvolvimento e Expansão (PIDE).

\footnotetext{
* Mestre em Educação pela Universidade Federal de Uberlândia (UFU). Uberlândia, Minas Gerais, Brasil.

** Professora doutora em Educaçáo pela Universidade Federal de Uberlândia (UFU). Uberlândia, Minas Gerais, Brasil.
} 


\section{The treatment that the educational inclusion of the public of special education receives in UFU's (Universidade Federal de Uberlândia) Developing and expanding institutional plans}

\section{Abstract}

We tried to identify the concept of inclusion fomented in the Developing and Expanding Institutional Plans (PIDEs) and if the goals and actions listed in the documents contribute to minimize physical and attitudinal barriers faced by disabled students in the institutional area. To accomplish this study, we chose the documental research, using, as a source of data, national official documents and the ones from the institution. The national ones were the regulatory laws which guide education in general, including the higher level. Therefore, laws, decrees, opinions, normative instructions, technical notes, etc., which were produced from 1996 to 2015, were used. Two versions of PIDE (developing and expanding institutional plans) (20082012/2010-2015), university council minutes, UFU's statute, internal regiment and other documents were used. We found that inclusion, under the effects of the historical process, becomes, nowadays, a state imperative and gets to universities, given that, according to the neoliberal vision, education becomes a condition so that people can operate with the inclusion logic in all their actions. We also found that, at UFU, this inclusive imperative can be seen in the documents (PIDEs) in two ways: through the social inclusion and the accessibility as a policy of students insertion and permanence.

Keywords: Inclusion; PIDE; UFU.

\section{A inclusão como estratégia do dispositivo da governamentalidade}

Ao se referir ao tema inclusão, pertinente se faz reconhecer que a defesa da cidadania e do direito à educação das denominadas, hoje, pessoas com deficiência ${ }^{1}$ é recente em nossa sociedade. A esse respeito, ressalta-se que alguns direitos das pessoas com deficiência, somente em meados do século XX podem ser apontados como elementos integrantes de políticas sociais.

Não se limitando à área educacional, a inclusão escolar tem sido discutida por diversos segmentos sociais; nas áreas do Direito, da Enfermagem, da Estatística, da Psicologia e da Medicina, que contribuem com a compreensão e estimulam a reflexão sobre o tema. No entanto, essa não é uma discussão tranquila, podendo a inclusão ser entendida de diversas formas, ou seja, têm-se muitas imagens a respeito do tema, o que pode ser verificado ao apresentarmos a maneira como alguns autores entendem a inclusão.

No contexto mundial, o princípio da inclusão "implicaria a construção de um processo bilateral no qual as pessoas excluídas e a sociedade buscam, em parceria, efetivar a equiparação de oportunidades para todos, [...] a diversidade seria respeitada e haveria aceitação e reconhecimento político das diferenças" (MENDES, 2006, p. 395). 
Mantoan (2005) entende ser urgente enfrentar o desafio da inclusão e colocar em açáo os meios pelos quais ela se concretize, sendo necessário promover uma reforma estrutural e organizacional de nossas escolas comuns e especiais. Afirma que ao conservadorismo é necessário responder com novas propostas que propiciem aos alunos uma escola "capaz de oferecer-lhes condiçôes de aprender na convivência com as diferenças e que valoriza o que consegue entender do mundo e de si mesmo" (MONTOAN, 2005, p. 28).

O professor Beyer (2006) aponta que a educação inclusiva caracteriza-se como princípio educacional, cujo conceito fundamental defende a heterogeneidade na classe escolar. Segundo o autor, o projeto pedagógico inclusivo evita dicotomias ou categorizaçôes, ou seja, diferenciaçôes entre alunos com e sem deficiência. O autor afirma que [...] "para tal abordagem educacional, não há dois grupos de alunos, porém apenas crianças e adolescentes que compóem a comunidade escolar e que apresentam as necessidades mais variadas" (BEYER, 2006, p.280).

Em entrevista concedida ao Centro de Referência em Educação (CRE) Ainscow define inclusão como sendo "a transformação do sistema educacional, de forma a encontrar meios de alcançar níveis que não estavam sendo contemplados”. O autor compreende a inclusão como um processo que ocorre em três níveis, sendo eles: presença, significa que não basta a presença do aluno na escola, ele precisa participar. $\mathrm{O}$ segundo é exatamente a participação e, nesse caso, é necessário dar condiçôes para que realmente o aluno participe das atividades escolares. $\mathrm{O}$ terceiro é a aquisição de conhecimentos, portanto inclusão significa o aluno estar na escola, participando, aprendendo e desenvolvendo suas potencialidades. "É identificar e sobrepujar as barreiras que impedem os alunos de adquirir conhecimentos acadêmicos. Essas barreiras podem ser: a organização da escola, o prédio, o currículo, a forma de ensinar e muitas vezes as barreiras que estão na mente das pessoas" (http://www.crmariocovas.sp.gov. br). Nesse trabalho, não pretendemos apresentar um conceito de inclusão escolar. A inclusão, no presente, apresenta-se como uma nova perspectiva para que a escola traga para dentro de seu espaço todos os alunos que estavam fora, através de políticas educacionais, de assistência e de programas governamentais. A partir disso, ela se configura como uma "verdade na educaçáo", sendo que o Ministério da Educação potencializa açóes em prol da inclusão, podendo-se citar a Política Nacional de Educação Especial na Perspectiva da Educação Inclusiva.

Pretendemos lançar um olhar suspeito sobre tal verdade e, a partir dos estudos Foucaultianos sobre a história da governamentalidade, analisar uma série de práticas de governamento que se difundem pela sociedade com o intuito de governá-la. Tais práticas podem ser consideradas inclusivas quando pretendem que todos os sujeitos participem dos jogos de poder dispostos em nossa sociedade. Buscaremos, assim, a compreensão da emergência da inclusão escolar como uma estratégia do dispositivo da governamentalidade, que age por meio de intervençóes educativas, médicas, psicológicas, sociais, para gerenciar e conduzir as condutas dos sujeitos, inserindo-a na ordem de imperativo de Estado. 
No final do século XVIII tem-se uma nova tecnologia de poder que Foucault (2005, p. 291) chama de "biopolítica da espécie humana". Trata-se de um conjunto de processos como a proporção dos nascimentos e dos óbitos, a taxa de reprodução, a fecundidade de uma população que juntamente com problemas econômicos e políticos constituíram, os primeiros objetos de saber e os primeiros alvos de controle dessa biopolítica. E nesse momento, se lança mão da mediçẫo estatística desses fenômenos com as primeiras demografias.

"A biopolítica lida com a populaçáo, e a população como problema político, como problema a um só tempo cientifico e político, como problema biológico e como problema de poder" (FOUCAULT, 2005, p. 293). É em relação aos fenômenos como a velhice, os acidentes, as enfermidades, as anomalias diversas que a biopolítica vai introduzir não somente instituiçôes de assistência, mas mecanismos mais sutis, mais racionais economicamente. Nessa operação que funciona uma tecnologia regulamentadora da população, pode-se citar a lei que "define formas de intervençôes gerais exclusivas de medidas particulares, individuais, excepcionais, e porque a participação dos governados na elaboraçáo da lei [...] constitui o sistema mais eficaz de economia governamental" (FOUCAULT, 1997, p. 93). É uma nova forma de governamentalidade.

A lei está no funcionamento móvel do regulamento. As legislaçôes operam como um conjunto de mecanismos que incidem sobre os processos de regulação da população. "A lei funciona cada vez mais como norma, e [...] a instituição judiciária se integra cada vez mais num contínuo de aparelhos cujas funçôes são, sobretudo, reguladoras" (FOUCAULT, 2003, p. 135). As regulamentaçôes operam tanto na normalização da população, quanto na regulação dos fenômenos sociais.

Com relação à educação, os próprios discursos de democratização do ensino, de acesso a todos, de garantia da qualidade, funcionam como reguladores da população, uma vez que o regulamento prevê que todos estejam na escola, sendo os sujeitos posicionados em diferentes classificaçôes nas diferentes modalidades da educação. Menezes (2010) contribui para essa compreensão, ao afirmar que pode-se dimensionar a educação como um dispositivo do biopoder, sendo essa relação ancorada no conceito de norma e normalização operada de formas diferentes. Ao considerar que a escolarização como instância universal e obrigatória, tem se mostrado como prática para o exercício da normalização, há possibilidade de perceber, por meio de análise nos registros escolares, deslocamentos dessas noçóes (norma e normalização) na sociedade de seguridade, considerando-se as diferentes formas de governamentalidade.

A escola, encaminhando o projeto da modernidade, se mantém até os dias de hoje como instituição educacional fundamental, encarregada de ser a mediadora entre o indivíduo e aquilo que ele deve ser e conhecer. "Encarregada de humanizar e corrigir os indivíduos, a escola moderna investe na disciplina tendo a função de transformar a animalidade em humanidade e estimular as qualidades naturais da humanidade" (LOPES, FABRIS, 2013, p.36). 
Ao abrir-se aos que eram marginalizados por questōes físicas ou político-econômicas, a escola estabelece um panorama de controle muito refinado, movido por necessidades econômicas que, por exemplo, determinam ações em que não é mais produtivo que as pessoas com deficiência fiquem separadas ou enclausuradas, buscando a normalizaçáo de todos e de cada um. Nessa fase a escola possui papel fundamental, tendo como tarefa principal regular as condutas e os comportamentos para atingir o controle e evitar o risco social. Afinal, pode-se pensar que a institucionalização dos sistemas de ensino pretendem a formação de tipos específicos de subjetividades, capazes de autogestão para a produção da sociedade capitalista e a formação de trabalhadores a partir de saberes nacionalmente instituídos a fim de evitar o risco social.

Lopes e Fabris (2013) afirmam que a escola é a instituição que mais tem se mostrado produtiva na vigilância e no controle dos indivíduos e na preparação de cada um para viver em sociedade. Pode-se, assim, pensar a escola dentro de uma relação permanente com os processos de inclusão e normalização cada vez mais atuais devido aos próprios movimentos sociais que, ao se ressignificarem, atualizam o conceito e o estabelecimento da norma. E a norma aqui, refere-se ao acesso de todos à escola. Nesse sentido, as leis (decretos, emendas constitucionais, normativas, pareceres) funcionam no processo de normalização, regulando essa prática. Assim, a preocupação com a educação inclusiva é algo que merece destaque na educação superior, refletindo sobre a seguinte questão: de que maneira a inclusão se faz presente no planejamento das instituiçôes de ensino superior, em específico na UFU, lócus desta pesquisa?

$\mathrm{Na}$ busca de documentos próprios da UFU que tratassem do assunto inclusão, entramos em contato com o Plano Institucional de Desenvolvimento e Expansão (PIDE). Esse documento faz parte das exigências do Ministério da Educação, que o inseriu como parte integrante do processo avaliativo das Instituiçóes de Ensino Superior (IES). O planejamento estratégico, convencionalmente denominado de Plano de Desenvolvimento Institucional (PDI), foi considerado um dos principais eixos de referência para a avaliação das Instituiçôes, com a intenção de dotá-las de um instrumento de planejamento capaz de responder às demandas sociais que lhes eram impostas. Na UFU, esse documento recebeu o nome de PIDE. Na gestão organizacional, um aspecto importante refere-se ao planejamento estratégico, por se caracterizar como um processo capaz de gerar reflexão sobre o fazer da instituição e seu desempenho, para que consiga atingir seus objetivos. Nesse sentido, o planejamento estratégico nas instituiçóes torna-se relevante, na perspectiva em que pode corroborar para que se evite uma dicotomia entre a intenção e a ação no cumprimento de seus objetivos e metas. O PDI, como um instrumento de planejamento estratégico das Instituiçôes de Educação Superior (IES), fornece relevantes informaçôes sobre elas: quanto à sua filosofia de trabalho, à missão que propóem cumprir, às diretrizes pedagógicas que orientam suas açôes, trazendo em sua composição, para um período de cinco anos, objetivos e metas que as IES se comprometem a realizar. 
Diante disso, o presente trabalho objetivou analisar em que medida a inclusão é considerada pela Universidade Federal de Uberlândia (UFU) em seu Plano Institucional de Desenvolvimento e Expansão, de modo a compreender como a estratégia do dispositivo da governamentalidade, a inclusão, se fazem presentes no planejamento dessa Instituição no período de 2008 a 2015. Desse objetivo, decorrem outros mais específicos, originários do desdobramento da questão central deste estudo, e que consistem em identificar e analisar no período de 2008 a 2015, nos PIDEs da UFU: a) o conceito de inclusão fomentado nos PIDEs; b) a coerência destes documentos com a legislação federal para a educação especial relacionada à educação superior; c) açôes inclusivas previstas nos PIDEs e seus desdobramentos na instituição no tocante ao ensino, à pesquisa e à extensão.

Portanto, para realização deste trabalho, optou-se pela pesquisa documental em que escolhemos trabalhar, como fonte de dados, os documentos oficiais nacionais e da instituição, por se mostrarem apropriados aos objetivos propostos. Os nacionais foram as legislações reguladoras e orientadoras para a educação em geral e para a superior, portanto foram tomados as leis, decretos, pareceres, instruçôes normativas, notas técnicas, etc. produzidas de 1996 a 2015; e como documentos institucionais, foram utilizadas as duas versóes do PIDE, no período de 2008-2012 e no período de 2010-2015, atas do Conselho Universitário (CONSUN), Estatuto UFU, Regimento Interno e outros documentos que se fizeram necessários à medida que se desenvolveu a pesquisa.

\section{Inclusão na Universidade Federal de Uberlândia - metas dos $\operatorname{PIDE}(s)$}

A inclusão não é algo em que sempre se pensou, principalmente quando se refere ao ensino superior. Os dados do Censo Escolar, referentes a 2013, ilustram bem essa situação. O total de 653.378 estudantes com deficiência na rede de ensino básico em todo o país representa apenas pouco mais de 1,62\% do total de matrículas na educação básica. Considerando o decréscimo importante de matrículas deste segmento no ensino médio, não causa estranhamento que o número de estudantes com deficiência matriculados no ensino superior seja inferior a $0,5 \%$ (meio por cento).

$\mathrm{Na}$ cidade de Uberlândia, pesquisa ${ }^{2}$ realizada pelo Centro de Pesquisas Econômico-Sociais UFU (CEPES), nos anos de 2004 e, posteriormente em 2008, numa população de $3.581 \mathrm{PCD}$, aponta as seguintes porcentagens em relaçáo à escolaridade: $\mathrm{PCD}^{3}$ que concluíram o Ensino Fundamental (8,27\% e 6,74\%, respectivamente); o Ensino Médio (11,78\% e 11,74\%); Superior Incompleto (2,26\% e 1,96\%) e Superior Completo $(1,70 \%$ e $1,34 \%)$. A pesquisa apontou também que em todos os tipos de alteração ou deficiência, o número de pessoas com Pós-Graduação é menor que $1 \%$. Embora esses dados não sejam atuais, pode-se ter uma noção do quantitativo de PCD no ensino superior nesta cidade.

Em 2014, em pesquisa realizada pela UFU quanto ao perfil dos estudantes, os dados apresentados a respeito dos discentes, segundo os tipos de deficiência por condição de matrícula (veterano e ingressante), mostram que, de um total de 21.309 estudantes, 96\% não apresenta qualquer tipo de deficiência. O tipo de deficiência mais frequente é a perda parcial de visão, que acomete $1,51 \%$ dos graduandos, se- 
guido por perda parcial de audição $(0,61 \%)$, deficiência física $(0,29 \%)$, deficiência mental $(0,5 \%)$, cegueira $(0,03)$ e surdez $(0,02)$. Essa pesquisa apontou também o significativo percentual de graduandos que respondeu a questão de forma inconsistente (por exemplo, assinalaram "sem deficiência" e ao mesmo tempo "surdez"): 1,10\%.

Sobre os dados apresentados acima, é importante salientar que, quanto ao número de estudantes com deficiência na UFU, faltam dados mais precisos, já que não foi realizada nenhuma pesquisa especificamente direcionada a essa população, que permita a construçáo de um banco de dados para identificar o perfil desses estudantes.

Relacionando esses dados com as açóes e metas apresentadas nos PIDE(s) UFU com relação à educação inclusiva, foram encontrados alguns dados interessantes. No primeiro PIDE (2008-2012), foram apresentadas seis ações voltadas para o público da educação especial; e no segundo, sete. São basicamente as mesmas, sendo que no segundo aparece a demanda da Escola de Educação Básica da UFU - Eseba. As metas e ações apresentadas nos PIDEs da UFU sinalizam uma exigência da legislação quanto à sua elaboração. $\mathrm{O}$ que se apresenta em relação à educação especial são açóes que fazem parte da proposta de trabalho do Cepae ${ }^{\underline{4}}$ e que, por exigência legal foram incorporadas nesse documento.

Verificando outros aspectos do PIDE, constatamos que a palavra inclusão se repete no texto vinte e uma vezes com significados distintos. Em algumas partes do texto, a palavra inclusão foi empregada com o significado de "inserção, ação de acrescentar" (dicionário online); a maior incidência da palavra inclusão aparece como proposta de inclusão social (oito repetiçóes); somente um enfoque é dado para área da educação especial e a inclusão escolar.

Diante das colocações acima, recorremos à dissertação de Provin (2011), que discute como o imperativo da inclusão na Contemporaneidade vem movimentando não somente a sociedade e as escolas, mas também as Universidades. Mediante esse imperativo, as IFES e, podemos afirmar, a UFU, intencionam viver processos mais inclusivos e criar uma "atitude de inclusão" (PROVIN, 2011, p.100). Foucault (2005) utiliza o conceito de atitude para definir a Modernidade como sendo [...] "um modo de relaçáo que concerne à atualidade; uma maneira de pensar e de sentir, uma maneira também de agir e se conduzir que, ao mesmo tempo, marca uma pertinência e se apresenta como uma tarefa". (FOUCAULT, 2005, p. 341-342). Ainda, para Provin (2011) a atitude também pode ser entendida como uma escolha, uma tomada de posição sobre algo que reflete o comprometimento de alguém consigo mesmo e com o outro. Trazendo esse conceito para o contexto das instituiçóes de ensino, em especial a UFU, percebe-se que não se pode ainda falar em atitudes de inclusão institucionais. O PIDE, esse documento de ordenamento da instituição que regulamenta, orienta e controla as açôes em um determinado período, tanto pela ausência de informaçóes sobre a sua elaboração quanto pelo que o seu conteúdo silencia a respeito da inclusão, pouco contribui para a assunção de uma política inclusiva. O que se verifica, na UFU, são açóes de inclusão (como as descritas no PIDE) e que, desenvolvidas por algumas pessoas, muitas vezes de forma isolada, não logram o sucesso pretendido e mantêm ou reafirmam a sujeição dos sujeitos da inclusão. 
Com base nos estudos foucaultianos, entendemos o tema inclusão como uma estratégia, ou seja, como constituído de mecanismos utilizados nas relaçóes de poder, com o objetivo de introduzir todos no jogo econômico; fazendo com que cada um se responsabilize por prover suas necessidades, suas aprendizagens. Trata-se de enxergar que a inclusão apresenta uma intencionalidade política de organização social, e foi se configurando mediante diferentes práticas sociais, como um modo de regular as condutas do sujeito para que ninguém se veja como dependente ou fique de fora dos jogos de mercado.

Embora sejam dois campos com abordagens teóricas distintas, encontramos uma forma possível de articular essa noção de inclusão com os estudos referentes à gestão e planejamento estratégico nas IES, na medida em que, pelas ferramentas metodológicas da governamentalidade, conseguimos vislumbrar que entram em açáo, diversos dispositivos que produzem efeitos no cotidiano institucional. As estratégias dos dispositivos da governamentalidade, a inclusão e o PDI, são fortemente atravessados pelos discursos empresarial e educacional e articulados para alcançar objetivos comprometidos com a sociedade neoliberal, na qual as IES são constituídas e a qual elas constituem, numa relação de imanência. As referidas estratégias dos dispositivos de governamento agem de forma sutil e produtiva, através de práticas sustentadas por discursos que, hoje, possuem um estatuto de verdade, tornando-se inquestionáveis, na maioria das vezes.

Constatamos que a inclusão, sob os efeitos do processo histórico, torna-se, na atualidade, um imperativo do Estado, visando a conquista. Dentre elas, a de minimizar as inúmeras práticas excludentes, que atingem vários segmentos sociais e, assim, combater as sequelas originárias do processo de exclusão, que ocorre por distintas razóes, tais como as relacionadas a gênero, deficiências, etnia e condiçóes econômicas. Constatamos também que o imperativo da inclusão chega às universidades, dado que, segundo a visão neoliberal, a educação passa a ser condição para que as pessoas possam operar com a lógica da inclusão em todas as suas açôes.

Verificou-se que na UFU, esse imperativo inclusivo se verifica nos documentos (PIDEs) de duas maneiras: através da inclusão social e da acessibilidade como política de inserção e permanência dos estudantes. O PIDE UFU dá uma ênfase maior na inclusão social, sendo que o Conselho Universitário (CONSUN), desde o ano de 2009, estabelece a política de assistência estudantil, sem, no entanto, contemplar o grupo de estudantes com deficiência em suas necessidades específicas. A UFU, desde 2013, aderiu à Lei das Cotas, em que se reserva 50\% das vagas, por curso e turno, para estudantes da rede pública de ensino. No entanto, nessa instituiçáo, não foi disponibilizada reserva de vagas para o grupo de estudantes da Educação especial, embora tenha sido sugerida pelo Ministério Público Federal (MPF).

Além disso, com relação à acessibilidade como forma de acesso e permanência, nenhuma política foi estabelecida na UFU, sendo que a maior parte (senão a totalidade) das providências adotadas sobre o assunto decorreu de determinaçôes judiciais para que direitos mínimos fossem assegurados aos estudantes com deficiência. 
Nas duas versões do PIDE, a UFU reconhece não ter uma política inclusiva. Entretanto, podemos inferir que a inclusão, em realidade, não é uma área de interesse e, assim, somente por imposição judicial a instituição atende o mínimo determinado; pois as discussões sobre o documento foram iniciadas em 2002, formalizada uma comissão em 2005 e, após uma década, nenhuma providência a favor desse público foi concretizada. Ou seja, assim como as IES em geral, a UFU não escolheu voluntariamente ser inclusiva, mas a inclusão como imperativo implica que nenhuma instituição possa renunciar a ela.

Outra realidade que demonstra o desinteresse da UFU pela inclusão é o fato de deixar a cargo do Cepae a responsabilidade pela acessibilidade, em todos os sentidos, sem ao menos dar um reconhecimento institucional nem oferecer condiçóes para uma melhor atuação desse setor. Desta forma, a UFU se desobriga como instituição, resguardando-se pelas açóes adotadas pelo Cepae; e ainda atribui, a esse setor, toda a responsabilidade por fracassos e morosidade na elaboração e formulação da política de acessibilidade.

Vimos que o conceito de in/exclusão encontra-se na realidade da UFU. Para o modelo de gestão capitalista, no qual a instituição está inserida e pelo qual é gerida, não é interessante manter a exclusão. Assim, a UFU passa a operar a partir de um modelo de estado que se propóe a transformar todos e qualquer um em sujeitos; não em sujeitos de direito, mas em sujeitos de consumo, pois todos devem participar dos jogos de mercado. Para isso, a estratégia do dispositivo utilizado é a inclusão. Ou seja, a ideia de inclusão, da qual se apropria o neoliberalismo nas sociedades contemporâneas, passa a ser um imperativo de estado que atua na transformação dos sujeitos em consumidores, não somente de mercadorias e bens físicos, mas em consumidores de bens subjetivos, de desejos.

Trazendo essa análise para a UFU, hoje, essa instituição está aberta para receber grupos anteriormente excluídos, como as pessoas com deficiência, através de estratégias e serviços que são oferecidos, tais como: adaptaçóes das provas nos processos seletivos, intérpretes de libras, elevadores nos diversos blocos, entre outros. No entanto, a estratégia do dispositivo da governamentalidade, a inclusão, ao mesmo tempo em que representa um avanço na conquista de direitos, representa também uma armadilha, pois, do ponto de vista da formulação de políticas, ele continua alimentando a exclusão, dado que, enquanto houver necessidade de uma política de inclusão, há alguém que ficou de fora. $\mathrm{Na}$ UFU, a estratégia do dispositivo da governamentalidade, a inclusão, inserido no PIDE faz gerar necessidade política e faz parecer que essa necessidade política é aceita e atende as necessidades das pessoas com deficiência; quando, em realidade, as políticas já existentes mobilizam e reforçam o que se quer combater, que são os processos de discriminação, de preconceito e de exclusão.

Náo se pode afirmar que nada foi feito pela inclusão na UFU, já que a instituição cumpriu algumas determinações legais como: disponibilização de intérpretes da língua de sinais, construção de rampas, instalação de elevadores, construção de algumas vias podotáteis, entre outras. Entretanto, muitos recursos oferecidos são pre- 
cários, improvisados, como é o caso de rampas fora do padrão e de elevadores inacabados e/ou sem funcionamento. Na biblioteca, por exemplo, é necessário aguardar até que um funcionário que tenha a chave do elevador possa atender, ou seja, a pessoa com deficiência fica sempre dependente, não tendo o acesso imediato. Os intérpretes da língua de sinais não são suficientes para atender todos os eventos e, por vezes, há esquecimento quanto ao agendamento desses serviços; provas são aplicadas em blocos que náo possuem rampas, de forma que as pessoas com deficiência que utilizam cadeiras de rodas dependem da boa vontade de pessoas para carregá-las. Há muito por realizar.

\section{Referências}

AINSCOW, M. O que significa inclusão? Disponível em: http://www.crmariocovas.sp.gov.br.> Acesso em: 20 dez. 2015 .

BEYER, H. O. Educação Inclusiva ou Integração Escolar? Implicaçōes pedagógicas dos conceitos como rupturas paradigmáticas. In: Ensaios pedagógicos. Brasília: Ministério da Educação, Secretaria de Educação Especial, 2006.

FOUCAULT, Michel. Ditos e Escritos: Arqueologia das ciências e história dos sistemas de pensamento. 2. ed. Rio de Janeiro: Forense Universitária, 2005.

FOUCAULT, Michel. Os Anormais: curso no Collège de France (1974 - 1975). São Paulo: Martins Fontes, 2001.

LOPES, M. C, FABRIS, E. H. Inclusáo \& Educaçáo. Belo Horizonte, Autêntica Editora, 2013.

LOPES, M. C, MORGANA, D. H (Orgs). Inclusão Escolar: conjunto de práticas que governam. Belo Horizonte, Autêntica Editora, 2009.

MANTOAN, M. T. E. A Hora da Virada. In: Inclusão - Revista da Educação Especial. Brasília: Ministério da Educação, Secretaria de Educação Especial. Out/2005. p. 24-28.

MENDES, E. G. A radicalização do debate sobre inclusão escolar no Brasil. Revista Brasileira de Educaçáo, v. 11 n. 33 set./dez. 2006

MENEZES, E. C. P. A maquinaria escolar na produçáo de subjetividades para uma sociedade inclusiva. 2011. 189 f. Tese (Doutorado em Educação) - Universidade do Vale do Rio dos Sinos. São Leopoldo..

PROVIN, P. O imperativo da inclusão nas Universidades Comunitárias Gaúchas: produzindo "atitudes de inclusão"? São Leopoldo: Unisinos, 2011, 159f. Dissertação (Mestrado em Educação - Programa de Pós-Graduaçáo em Educaçấo, Universidade do Vale do Rio dos Sinos, 2011.

UNIVERSIDADE FEDERAL DE UBERLÂNDIA. Plano Institucional de Desenvolvimento e Expansão PIDE - período 2008-2012. Anexo à Resolução 07/2009 do Conselho Universitário. Disponível em: http:// www.reitoria.ufu.br/Resolucoes/ataCONSUN-2009-7.pdf.

UNIVERSIDADE FEDERAL DE UBERLÂNDIA. Plano Institucional de Desenvolvimento e Expansão PIDE - período 2010-2015. Disponível em: http://www.pide.ufu.br/node/4.

VEIGA-NETO, Alfredo. Educação e governamentalidade neoliberal: novos dispositivos, novas subjetividades. In: PORTOCARRERO, Vera \& CASTELO BRANCO, Guilherme (org.). Retratos de Foucault. Rio de Janeiro: NAU, 2000. p. 179-217.

\section{Notas}

${ }^{1}$ Sassaki, em seu artigo "Como chamar as pessoas que têm deficiência?", informa que os movimentos mundiais de pessoas com deficiência, incluindo o Brasil, após debaterem o nome pelo qual querem ser chamadas, escolheram "pessoas com deficiência" em todos os idiomas. Esse termo faz parte do texto da Convençăo sobre os Direitos das Pessoas com Deficiência, adotado pela ONU em 13/12/2006 que no Brasil foi ratificado com equivalência de Emenda Constitucional pelo Decreto Legislativo n.186, de 09/07/2008, do Congresso Nacional. O texto pode ser encontrado em: SASSAKI, Romeu Kazumi. Como chamar as pessoas que têm deficiência? Revista da Sociedade Brasileira de Ostomizados, ano I, n. 1, $1^{\circ}$ sem. 2003, p.8-11. 
${ }^{2}$ A pesquisa realizada intitula-se: LEVANTAMENTO DE INFORMAÇÓES ECONÔMICO-SOCIAIS DAS PESSOAS COM DEFICIÊNCIA - LIESPDeficiência - UBERLÂNDIA/MG. Acesso em: http://www.uberlandia. mg.gov.br/uploads/cms_b_arquivos/2988.pdf.

${ }^{3} \mathrm{PCD}$ - Pessoas com Deficiência

${ }^{4}$ Destaca-se que o Centro de Ensino, Pesquisa, Extensão e Atendimento em Educaçấo Especial- Cepae/UFU existe na instituição desde 2003. Nestes seus doze anos de existência sempre funcionou como setor responsável pela acessibilidade em todos os sentidos na instituiçáo.

\section{Correspondência}

Márcia Guimarães de Freitas - Universidade Federal de Uberlândia. Av. João Naves de Ávila, 2121 - Santa Mônica, Uberlândia. CEP: 38400-902. Uberlândia, Minas Gerais, Brasil.

E-mail: marcia.gdefreitas@gmail.com - lazara@ufu.br

Recebido em 16 de dezembro de 2017

Aprovado em 12 de abril de 2018

\section{(c) (i) ()}

This work is licensed under a Creative Commons Attribution-NonCommercial 4.0 International (CC BY-NC 4.0) 
